\title{
Theoretical and clinical overview of affective temperaments in mood disorders
}

Xenia Gonda ${ }^{1}$ \& Gustavo H. Vázquez ${ }^{2}$

\section{Artículo}

Material original autorizado para la publicación en la revista Psicodebate. Facultad de Ciencias Sociales. Universidad de Palermo.

Recibido 01-07-2014 | Aceptado 15-07-2014

\section{Abstract}

Temperaments are imperturbable variations of personality, traits and ways of reacting to the environment that characterize individuals and remain constant throughout several different situations. Temperaments usually play a central role in determining emotional reactions, therefore several temperamental models have attempted to establish the potential relationship between temperaments and affective disorders. According to Hagop Akiskal, affective temperaments are subclinical and subaffective trait-like manifestations of affective disorders. Unlike several models of temperament which were exclusively developed theoretically in order to describe healthy human functioning, later extrapolated to capture the pathological domains of mental and behavioral features, the current model of affective temperaments was developed on classical traditions and mainly based on the observation of subjects with mood disorders and their healthy first degree relatives. There is accumulating evidence concerning the development of affective temperaments based on their adaptive evolutionary characteristics and genetic background, and normative data from large national studies on general and healthy samples indicate their universal characteristics. Studies in affective

1 Department of Clinical and Theoretical Mental Health Semmelweis University; Department of Pharmacodynamics, Semmelweis University; Neuropsychopharmacology and Neurochemistry Research Group, National Academy of Sciences and Semmelweis University, Budapest; Laboratory for Suicide Research and Prevention, National Institute for Psychiatry and Addictions, Budapest, Hungary; kendermagos@yahoo.com

2 Department of Neuroscience, University of Palermo, Buenos Aires, Argentina; International Consortium for Bipolar Disorders Research, Department of Psychiatry \& Neuroscience Program, Harvard Medical School, Boston, McLean Division of Massachusetts General Hospital, Belmont, MA, USA 
Gonda \& Vázquez I Psicodebate, 14(2) I 39-58.

patient populations indicate that the relationship between affective temperaments and affective illness is more complex than a simple extrapolation from psychopathology and mental health, and affective temperaments may represent a latent state of the staging model, playing a pathoplastic role in mood disorders determining their evolution, clinical features, main characteristics and outcome. A large body of data on affective temperaments has been published during the last decade, deserving a critical analysis presented in this overview.

Keywords: Affective temperaments - Bipolar Disorders - Bipolar Spectrum Mood Disorders - Personality. 
In order to be able to better diagnose psychiatric illnesses and to identify conditions which fall between categories, there has been a shift towards the spectrum concept of psychiatric illness in general and of affective and bipolar disorders in particular. This view may help to extend our understanding of the continuity of related pathological states also to the domain of non-clinical and subclinical presentations and to those manifestations which, although falling below the definition of bipolar illness, constitute a high risk or prodromal state, or may already cause significant suffering or increase the risk of worsening and later development of more serious forms of illness, therefore requiring professional attention, and, possibly, specific treatment. This spectrum concept of affective and bipolar illness also means extending the continuum to mental health and identifying those healthy states which carry the potential of later laying the base for developing illness possibly on a genetic, personality or behavioral basis. Also, understanding both ends and the whole span of this spectrum provides us with the opportunity to perform research on bipolar disorder in a continuum approach instead of a case-control perspective which latter could lead to ignoring important associations. Therefore identifying the healthier, nonaffected and subclinical portion of the bipolar spectrum which may also constitute latent stages of the illness is crucial for understanding, treating, predicting and also possible preventing these severely debilitating illnesses.

Akiskal and colleagues have proposed the concept of the soft bipolar spectrum which includes different manifestations of hypomania in addition to depressive states and also builds on the underlying temperamental dysregulation in the background of affective manifestations. Moreover, this may contribute to a more clinically sophisticated differentiation of bipolar illness with the introduction of new more detailed illness subtypes (Akiskal \& Mallya, 1987). Later on, besides these more sophisticated subtypes, the concept of affective temperaments was also introduced to dive further towards the less affected end of the bipolar spectrum.

Besides the classical spectrum model, the staging model of bipolar illness also argues for a continuum approach as opposed to categorical classification of bipolar disorder in order to predict evolution and prognosis and to determine the most appropriate treatment at the given stage to reduce symptoms and possibly prevent progression (Grande, Frey, Vieta, \& Kapczinski, 2013). Staging of bipolar illness is based on clinical assessment and functionality observable in affective patients, especially between major episodes. Currently in this theoretical model there are five stages, with 4 clinical stages in addition to a latent phase for those manifesting nonspecific affective symptoms (Grande et al., 2013). The latent stage includes those individuals who can be considered at an extremely high risk of developing bipolar illness but do not have yet any specific symptoms, only 
atypical prodromal signs including positive family history, anxiety, hyperphagia and hypersomnia, seasonal mood fluctuations, mood lability and irritability as well as psychomotor retardation, in addition to hyperthymic or cyclothymic temperamental makeup (Balanza-Martinez et al., 2008). As symptoms at this phase can be highly unspecific and further course and outcome unpredictable, it is strongly controversial if pharmacological treatment should be recommended, although may be useful in the treatment of subthreshold symptomatology that may be causing mild suffering or impact on functionality (Grande et al., 2013).

Although at this point there is no study yet available to test the definitive validity of the staging model and we have not got enough methods for operationalization, the description of this latent stage closely resembles several particular features commonly associated with the state characterized by the presence of predominant affective temperaments. There are several factors which link affective temperaments with affective illness, and argue for searching specific manifestations of affective temperaments as possible risk factor or precursor state for the development of major affective illnesses.

\section{Overview of the development of the affective temperament model}

Putative traits underlying those for bipolar disorders represent an adequate paradigm to conceptualize the potential connection between mental disorders and adaptive temperamental attributes (Akiskal \& Akiskal, 2005). Temperaments refer to temporally stable behavioral traits with strong affective reactivity and have been associated with the biological foundations of personality, such as activity levels, rhythms, moods, cognition and their variability. Affective temperaments not only could have a relevant role in the predisposition to major affective disorders but also represent the most prevalent phenotypic expression of the genes underlying bipolar disorders (Akiskal and Akiskal, 1992; Kelsoe, 2003). Origins of the modern concept for affective temperaments can be traced to the humoral theories described by Hippocrates (Akiskal, 1996), while later on the German psychiatrist Emil Kraepelin described four basic affective dispositions (depressive, manic, cyclothymic and irritable) supporting his temperamental hypothesis on the classic works of Galen, who previously stated the melancholic, choleric, phlegmatic and sanguine humors, and their imbalance and dysbalance, as the major origin of the different human illnesses. Kraepelin considered these basic affective temperaments as the subclinical forms of manic-depressive insanity, nowadays known as major affective disorders which could be found not only in mental illness patients but also among their healthy relatives (Kraepelin, 1921). Both Kraepelin and his German colleague Ernst Kretschmer considered 
that affective temperaments could predispose to endogenous psychosis or mood episodes, however, the latter postulated that the presence of a dominant temperament should be considered a variation of normal affectivity which could potentially lead to mental illness.

Combining these ancient preliminary ideas with applying extensive modern scientific and clinical observation and field research, Akiskal and collaborators developed the modern concept of affective temperaments to encompass the whole spectrum of affective disturbances from healthy emotional reactivity types to major affective illnesses. The model includes the four classical temperamental types supplemented with a fifth one, the anxious temperament. A detailed clinical description for each temperament and their assessment with a psychometrically valid instrument (TEMPS-A) can be found elsewhere (Akiskal \& Akiskal, 2005).

Akiskal considers the five affective temperaments as spectrums stretching from health to pathology, involved in characteristic patterns of healthy emotional reactivity on one end and different types of major affective disorders on the other (Akiskal \& Akiskal, 2007). In between it can be found the so called predominant affective temperaments, which, expressed in a marked form, can constitute the subclinical and subaffective manifestation of affective illnesses, and can be considered precursor or latent states which could represent high risk conditions, corresponding to latent phases of mood disorders.

\section{Clinical aspects of affective temperaments}

As detailed above, affective temperaments are conceptualized as part of the affective disorder spectrum, a notion which is widely supported by familial, genetic, biological and clinical studies. The affective spectrum describes a continuum between cyclothymia, bipolar II disorder and bipolar I disorder (Akiskal, Djenderedjian, Rosenthal, \& Khani, 1977; Evans et al., 2008); as well as subsyndromal depression, minor depression, dysthymia and unipolar major depression (Akiskal, Bitar, Puzantian, Rosenthal, \& Walker, 1978; Judd \& Akiskal, 2000; Lewinsohn, Klein, Durbin, Seeley, \& Rohde, 2003). Affective temperaments, besides constituting latent illness phases extending these spectrums towards the states of mental health, could play a pathoplastic role, determining and modeling the emergence and clinical evolution of affective disorders and several important disease characteristics, including such crucial core features as predominant polarity, symptomatic expression, long-term course and consequences, response and adherence to treatment and outcome as well (Vazquez \& Gonda, 2013). The relationship between affective temperaments and affective illness could be, however, rather more complex. 
Predominant affective temperaments are present in up to $20 \%$ of the healthy general population, ranging from $13 \%$ in Argentina to $20 \%$ in Germany (Vazquez, Tondo, Mazzarini, \& Gonda, 2012). Affective temperaments show a characteristic gender distribution, with both depressive and anxious temperaments being more common among females while hyperthymic is found more commonly among males in most large scale national studies (Vazquez et al., 2012). The higher prevalence of depressive and anxious temperaments among females in the general population correlates with the higher prevalence for unipolar major depression and anxiety disorders in women (Kuehner, 2003; Somers, Goldner, Waraich, \& Hsu, 2006), while higher prevalence of hyperthymic temperament among men is in line with the higher proportion of manic episodes reported among them (Baldassano et al., 2005). These findings also support the hypothesis that affective temperaments could be subclinical forms or precursors of those major psychiatric disorders which clearly display a particularly different gender distribution (Vazquez et al., 2012).

According to different studies in clinical samples, depressive temperament is usually more prevalent among major depressive patients, and hyperthymic as well as cyclothymic temperament is a particular affective characteristic for bipolar illness. Moreover, some studies have reported that cyclothymic temperament was found to be non-significantly higher in bipolar II disorder compared to both bipolar I illness and recurrent depressive disorder, and among these three major affective disorders there was no difference on the irritable temperament scores (Gassab, Mechri, Bacha, Gaddour, \& Gaha, 2008). As clinical studies report more subtle and complex association between affective temperaments and affective illness, it is increasingly noted that affective temperaments show important within-illness variations besides the well-known between-illness pattern. A more complex approach to detection and identification of affective temperaments within the above described basic constellations may allow for performing a more sophisticated classification of affective illness, predicting and determining subtypes and characteristics (Mazzarini et al., 2009).

Even in the case of unipolar major depression, presence of other affective temperaments besides the depressive temperament has a crucial role in determining the clinical picture, and the presence of other affective temperaments in patients with a major depressive episode may be valuable in predicting illness course and bipolar conversion. The presence of cyclothymic temperament in those cases of major depression has been related to atypical clinical features (Perugi, Toni, Travierso, \& Akiskal, 2003). In patients with recurrent major unipolar depression, higher scores of cyclothymic temperament are also associated with earlier age of onset, a higher number of previous depressive episodes, more psychotic and melancholic features, as well as suicidal ideations and attempts, 
which are predictive factors of bipolarity in recurrent depression (Mechri, La Kerkeni, Touati, Bacha, \& Gassab, 2011).

Temperament may be one of the major factors influencing features in the clinical evolution of bipolar disorder, with the number of episodes associated with higher depressive and lower hyperthymic temperament scores, and more marked presence of depressive temperament associated with a higher ratio of depressive episodes and the marked presence of hyperthymic temperament with manic episodes (Henry et al., 1999). Affective temperaments have been also shown to be related to age of onset in bipolar disorder (Oedegaard, Syrstad, Morken, Akiskal, \& Fasmer, 2009). Depressive temperament may prevail among bipolar I disorder patients with predominant depressive polarity, and hyperthymic temperament is commonly present in those bipolar disorder patients with manic predominant polarity (Henry et al., 1999). Bipolar disorder patients with predominant cyclothymic and hyperthymic temperament are significantly different along several relevant clinical and course features, including gender ratio, episode polarity and number of episodes, hospitalizations, suicidality, comorbid anxiety disorders, and personality disorders (Perugi et al., 2012). Furthermore, hyperthymic temperament was associated with psychotic features both in bipolar I and bipolar II illness (Gassab et al., 2008, Mazzarini et al., 2009). As for illness course, cyclothymic temperament has been related with a higher number for all types of affective bipolar episodes (Kochman et al., 2005) and is also related to poorer outcome (Cassano, Akiskal, Savino, Musetti, \& Perugi, 1992). Manic switches occur more commonly in bipolar disorder patients with hyperthymic temperament, while psychotic features among those subjects with an irritable temperament. Comorbidities among affective patients with a cyclothymic temperament are frequent, and irritable temperament is significantly associated with a manic first episode of the illness (Kesebir, Vahip, Akdeniz, \& Yuncu, 2005a). Higher scores of hyperthymic temperament are associated with higher risks for antidepressant induced mania in bipolar depressives (Tondo, Baldessarini, Vazquez, Lepri, \& Visioli, 2013; Henry, Sorbara, Lacoste, Gindre, \& Leboyer, 2001).

While in the case of bipolar type I disorder many different temperamental constellations may lie in the background, bipolar II disorder is more specifically related to cyclothymic temperament (Hantouche et al., 1998), and cyclothymic temperament is not only present in the majority of bipolar II patients but also has a predictive value for bipolar conversion from unipolar depression (Kochman et al., 2005, Akiskal et al., 1995). Among bipolar I patients, but not bipolar II, hyperthymic and depressive temperament scores were found to have a negative correlation. Hyperthymic temperament was negatively correlated with the number of depressive episodes and seasonal features in bipolar disorder type II patients (Gassab et al., 2008). 
Depressive, cyclothymic, irritable and anxious temperaments are significantly more frequent in affective patients with mixed episodes indicating a relationship between mixed affective episodes and simultaneous presence of inverse temperamental types (Rottig, Rottig, Brieger, \& Marneros, 2007). The presence of depressive temperament could also help distinguishing between mixed and pure manic states (Hantouche et al., 2001).

\section{Genetic and neurochemical background of affective temperaments}

An important feature of the staging model is assigning genetic, neurochemical, neuroanatomical, neurobiological and neurocognitive characteristics that differentiate between different stages of the illness (Berk et al., 2007; Kapczinski et al., 2009; Grande et al., 2013). Although we have limited findings to support the association of such factors with affective temperaments, there are some positive results reported, which also argue for affective temperaments as being latent phases of affective illness.

By definition, temperaments have a strong biological and genetic base (Bouchard, 1994; Cloninger, 1994) and this also seems to be the case for affective temperaments (Evans et al., 2005; Chiaroni, Hantouche, Gouvernet, Azorin, \& Akiskal, 2005). A more recent approach to bipolar disorder conceptualizes bipolar spectrum as a quantitative genetic trait with a continuous distribution instead of a qualitative one as suggested by a categorical approach (Evans et al., 2005) and bipolar disorder is most likely a polygenic trait emerging as a result of interactions between environmental factors and multiple genes, each with only a small effect on its own (Craddock \& Sklar, 2013; Evans et al., 2005). Those genes predisposing to bipolar disorders may give rise to phenotypes that continuously blend into normally seen constellations in healthy nonclinical populations, which can be described as normal variations of affective temperaments. As mentioned above, affective illnesses are genetic reservoirs for adaptive temperaments and traits (Akiskal \& Akiskal, 2007).

Several studies have demonstrated that healthy relatives of bipolar probands exhibit a higher degree of temperamental dysregulation than normal controls (Evans et al., 2005; Mendlowicz, Jean-Louis, Kelsoe, \& Akiskal, 2005), and that those temperamental traits would have a common genetic basis with bipolar disorder (Kelsoe, 2003). Familial genetic studies of affective disorder patients identified a strong aggregation of affective temperaments, mainly cyclothymic and, to a lesser degree, hyperthymic and anxious temperaments, among healthy first degree relatives of bipolar I patients, supporting the genetic basis of affective temperaments (Chiaroni et al. 2005; Evans et al., 2005, 2008; Kesebir et al., 
2005b; Mazzarini et al., 2009; Mendlowicz et al., 2005; Vazquez et al., 2008). These subaffective cyclothymic traits could serve as a potential vulnerability marker, and give support for the subthreshold forms and softest end of the bipolar spectrum (Akiskal \& Pinto, 1999). There are reasonable arguments that cyclothymic temperament could contribute to a broad phenotypic definition of the bipolar condition (Chiaroni et al., 2005; Kochman et al., 2005) and would be considered as a preliminary or latent stage for full-blown bipolar disorder.

However, in spite of these findings and the increasing attention for affective temperaments both in clinical and personality research fields, our knowledge concerning their genetic background needs further investigation. In a seminal study, Gonda and coworkers reported a significant association between the s allele of the 5-HTTLPR polymorphism of the serotonin transporter gene and affective temperaments carrying a depressive component (depressive, cyclothymic, irritable and anxious) (Gonda et al., 2006), which was not confirmed by some subsequent studies (Kang, Burmeister, Shedden, \& Sen, 2008; Landaas et al., 2011). The role of the 5-HTTLPR s allele was not surprising, since this allele has been found to be associated with anxiety (Homberg \& Lesch, 2011; Sen, Burmeister, \& Ghosh, 2004) and neuroticism-related traits (Gonda et al., 2009) as well as unipolar (Clarke, Flint, Attwood, \& Munafo, 2010) and bipolar affective disorders (Levinson, 2006). The 5-HTTLPR s allele is thought to exert its influence on the emergence of depression by mediating the effect of life stress and adverse life events (Caspi et al., 2003, Caspi, Hariri, Holmes, Uher, \& Moffitt, 2010; Karg, Burmeister, Shedden, \& Sen, 2011), and emotional reactivity is one crucial feature encompassed by affective temperaments. Moreover, a significant interaction effect between the 5-HTTLPR and the cannabinoid 1 receptor gene promoter polymorphism (CNR1) was later reported for anxious temperament (Lazary et al., 2009) further supporting the strong genetic determination of affective temperaments as well as their claim for constituting latent stages for affective illness.

Besides genes encoding for elements of the serotonergic system, other monoaminergic genes often emerge as potential candidates for playing a role in determining temperaments. A Korean study reported a positive association between the DRD4 gene and irritable and cyclothymic temperaments in healthy male subjects (Kang et al., 2008). Both the irritable and cyclothymic temperaments are classically conceptualized as mixed temperamental subtypes, incorporating both depressive and hyperthymic features, simultaneously in case of the irritable, and alternatively in case of the cyclothymic temperament (Kraepelin, 1921), so the association with the DRD4 gene may suggest a potential link between this receptor and the hyperthymic traits, such as in the Gonda et al. (2006) study the 5-HTTLPR s allele was associated with the depressive component of affective 
temperaments. The depressive temperament was also significantly associated with the most frequent haplotype of the oxitocyn receptor gene in a healthy Japanese sample (Kawamura et al., 2010). One study reported a positive association between cyclothymic temperament and a chromosomal locus on 18p11 in bipolar disorder families, and other linkage peaks with potential regions of interest were also detected on chromosomes 3 and 7 (Evans et al., 2008).

The remaining few studies addressing the genetic background of affective temperaments yielded negative findings. There is increasing attention concerning the association of the brain-derived neurotrophic factor (BDNF) and affective disorders with some positive results (Lohoff, 2010; Neves-Pereira et al., 2002; Sklar et al., $2002)$, and there are similarly emerging results for the glycogen synthase kinase $3 \beta$ (GSK3 $\beta$ ) rs6782799 polymorphism (Zhang et al., 2010) and the rs2267665 polymorphism of the PPARD (peroxisome proliferative activated receptor delta) gene in the Wnt signaling pathway, which may also be implicated on the pathophysiology of affective disorders (Zandi et al., 2008). However, a recent study found no association between these polymorphisms and affective temperaments in a healthy population (Tsutsumi et al., 2011), although it should be noted that this study applied a small sample on a Japanese subjects, and it must be kept in mind that genetic associations are ethnicity-specific, and also that the distribution of affective temperament scores in Japan markedly differ from those in other countries, with typically much lower scores (Matsumoto et al., 2005); therefore, the results of this particular Japanese study may not be generalized to other non clinical populations.

The different studies described above indicate that there may be a common genetic heterogeneity in the background of affective temperaments and different major affective illness manifestations and syndromes, so the delineation of the genetic correlates of affective temperaments would help us deeper understand the genetic contributors and thus the etiopathogenic foundation of affective disorders. However, selecting candidate genes simply by extrapolating from polymorphisms known to be associated with affective disorders yielded mixed results, possibly because both the genetic background and the phenotypic expression of affective temperaments are present in a more diluted form among healthy samples (Akiskal \& Akiskal, 2005).

The potential association between affective temperaments and neurotransmitter function and neuroanatomical structures has been also understudied so far. In one study in patients with major mood disorders predominantly depressive temperamental profiles characterized by high depressive, cyclothymic, anxious and irritable as well as low hyperthymic temperament scores were found to be associated with different patterns of white matter hyperintensities in the brain, indicating a positive association between some affective temperaments subtypes and specific alterations on subcortical brain regions (Serafini et al., 2011). 
In another recent series of papers an association between affective temperaments and date of birth has been reported with characteristic patterns (Rihmer et al., 2011), and interestingly this pattern of association corresponds to the birth season pattern earlier reported for bipolar I and II patients in a small clinical sample (Rihmer, 1980). Birth season is an important marker and a proxy variable for several environmental factors varying with seasons and active during the time of conception, gestation or birth (Chotai, Jonasson, Hagglof, \& Adolfsson, 2002). It is not yet known which of the possible varying factors exerts an effect and during which period of importance, but an association with season of birth has already been reported in case of various somatic and neuropsychiatric illnesses as well as healthy psychological traits (Rihmer et al., 2011) and one likely explanation is that birth season exerts its influence via influencing monoaminergic neurotransmission neurodevelopment (Chotai, Murphy, \& Constantino 2006).

Several biomarkers have been found to be associated with progression of bipolar disorder but not with the latent phase; therefore it is believed that polymorphisms conferring increased susceptibility for bipolar illness may be important as biomarkers signaling this phase (Kapczinski et al., 2009). However, biochemical changes associated with the clinical features of the latent phase including mood and anxiety symptoms and temperamental dysregulation may be important already in this stage. 


\section{References}

Akiskal, H. S. (1996). The temperamental foundations of affective disorders. London: Gaskell.

Akiskal, H. S. \& Akiskal, K. K. (1992). Cyclothymic, hyperthymic and depressive temperaments as subaffective variants of mood disorders. En A. Tasman \& M. B. Riba (Eds.) Annual Review, vol. II. Washington, D.C.: American Psychiatric Press.

Akiskal, H. S. \& Akiskal, K. K. (2007). In search of Aristotle: temperament, human nature, melancholia, creativity and eminence. Journal Affective Disorders, 100, 1-6.

Akiskal, H. S., Bitar, A. H., Puzantian, V. R., Rosenthal, T. L., \& Walker, P. W. (1978). The nosological status of neurotic depression: a prospective threeto four-year follow-up examination in light of the primary-secondary and unipolar-bipolar dichotomies. Archives of General Psychiatry, 35, 756-66.

Akiskal, H. S., Djenderedjian, A. M., Rosenthal, R. H., \& Khani, M. K. (1977). Cyclothymic disorder: validating criteria for inclusion in the bipolar affective group. The American journal of psychiatry, 134, 1227-1233.

Akiskal, H. S. \& Mallya, G. (1987). Criteria for the "soft" bipolar spectrum: treatment implications. Psychopharmacology Bulletin, 23, 68-73.

Akiskal, H. S., Maser, J. D., Zeller, P. J., Endicott, J., Coryell, W., Keller, M., ... Goodwin, F. (1995). Switching from 'unipolar' to Bipolar II. An 11-Year Prospective-Study of Clinical and Temperamental Predictors in 559 Patients. Archives of General Psychiatry, 52, 114-123.

Akiskal, H. S. \& Pinto, O. (1999). The evolving bipolar spectrum. Prototypes I, II, III, and IV. Psychiatric Clinics of North America, 22(3), 517-534.

Akiskal, K. K. \& Akiskal, H. S. (2005). The theoretical underpinnings of affective temperaments: implications for evolutionary foundations of bipolar disorder and human nature. Journal of Affective Disorders, 85, 231-239.

Balanza-Martinez, V., Rubio, C., Selva-Vera, G., Martinez-Aran, A., SanchezMoreno, J., Salazar-Fraile, J., ... Tabares-Seisdedos, R. (2008). Neurocognitive endophenotypes (Endophenocognitypes) from studies of relatives of bipolar disorder subjects: A systematic review. Neuroscience \& Biobehavioral Reviews, 32, 1426-1438. 
Baldassano, C. F., Marangell, L. B., Gyulai, L., Ghaemi, S. N., Joffe, H., Kim, D. R., ... Cohen, L. S. (2005). Gender differences in bipolar disorder: retrospective data from the first 500 STEP-BD participants. Bipolar Disorders, 7, 465-70.

Berk, M., Conus, P., Lucas, N., Hallam, K., Malhi, G. S., Dodd, S., ... Mcgorry, P. (2007). Setting the stage: from prodrome to treatment resistance in bipolar disorder. Bipolar Disorders, 9, 671-678.

Bouchard, T. J., Jr. (1994). Genes, environment, and personality. Science, 264, 1700-1701.

Caspi, A., Hariri, A. R., Holmes, A., Uher, R., \& Moffitt, T. E. (2010). Genetic Sensitivity to the Environment: The Case of the Serotonin Transporter Gene and Its Implications for Studying Complex Diseases and Traits. American Journal of Psychiatry, 167, 509-527.

Caspi, A., Sugden, K., Moffitt, T. E., Taylor, A., Craig, I. W., Harrington, H., ... Poulton, R. (2003). Influence of life stress on depression: moderation by a polymorphism in the 5-HTT gene. Science, 301, 386-389.

Cassano, G. B., Akiskal, H. S., Savino, M., Musetti, L., \& Perugi, G. (1992). Proposed subtypes of bipolar II and related disorders: with hypomanic episodes (or cyclothymia) and with hyperthymic temperament. Journal of Affective Disorders, 26, 127-40.

Chiaroni, P., Hantouche, E. G., Gouvernet, J., Azorin, J. M., \& Akiskal, H. S. (2005). The cyclothymic temperament in healthy controls and familially at risk individuals for mood disorder: endophenotype for genetic studies? $J$ Affect Disorders, 85, 135-145.

Chotai, J., Jonasson, M., Hagglof, B., \& Adolfsson, R. (2002). The Temperament Scale of Novelty Seeking in adolescents shows an association with season of birth opposite to that in adults. Psychiatry Research, 111, 45-54.

Chotai, J., Murphy, D. L., \& Constantino, J. N. (2006). Cerebrospinal fluid monoamine metabolite levels in human newborn infants born in winter differ from those born in summer Psychiatry Research, 145, 189-97.

Clarke, H., Flint, J., Attwood, A. S., \& Munafo, M. R. (2010). Association of the 5HTTLPR genotype and unipolar depression: a meta-analysis. Psychological Medicine, 40, 1767-78. 
Cloninger, C. R. (1994). Temperament and personality. Current Opinion in Neurobiology, 4, 266-73.

Craddock, N. \& Sklar, P. (2013). Genetics of bipolar disorder. Lancet, 381, 16541662.

Evans, L., Akiskal, H. S., Keck, P. E., Mcelroy, S. L., Sadovnick, A. D., Remick, R. A., \& Kelsoe, J. R. (2005). Familiality of temperament in bipolar disorder: support for a genetic spectrum. Journal of Affective Disorders, 85, 153-168.

Evans, L. M., Akiskal, H. S., Greenwood, T. A., Nievergelt, C. M., Keck, P. E., Mcelroy, S. L., ... Kelsoe, J. R. (2008). Suggestive linkage of a chromosomal locus on 18p11 to cyclothymic temperament in bipolar disorder families. American Journal of Medical Genetics Part B, 147B, 326-332.

Gassab, L., Mechri, A., Bacha, M., Gaddour, N., \& Gaha, L. (2008). Affective temperaments in the bipolar and unipolar disorders: distinctive profiles and relationship with clinical features. Encephale, 34, 477-82.

Gonda, X., Fountoulakis, K. N., Juhasz, G., Rihmer, Z., Lazary, J., Laszik, A., ... Bagdy, G. (2009). Association of the s allele of the 5-HTTLPR with neuroticism-related traits and temperaments in a psychiatrically healthy population. European Archives of Psychiatry and Clinical Neuroscience, 259, 106-13.

Gonda, X., Rihmer, Z., Zsombok, T., Bagdy, G., Akiskal, K. K., \& Akiskal, H. S. (2006). The 5HTTLPR polymorphism of the serotonin transporter gene is associated with affective temperaments as measured by TEMPS-A. Journal of Affective Disorders, 91, 125-31.

Grande, I., Frey, B. N., Vieta, E., \& Kapczinski, F. (2013). Soft Bipolar Spectrum and Staging in Bipolar Disorder. Current Psychiatry Reviews, 9, 33-40.

Hantouche, E. G., Akiskal, H. S., Lancrenon, S., Allilaire, J. F., Sechter, D., Azorin, J.M., \& Chatenet-Duchene, L. (1998). Systematic clinical methodology for validating bipolar-II disorder: data in mid-stream from a French national multi-site study (EPIDEP). Journal of Affective Disorders, 50, 163-173.

Hantouche, E. G., Allilaire, J. P., Bourgeois, M. L., Azorin, J. M., Sechter, D., Chatenet-Duchene, L., \& Lancrenon, S. (2001). The feasibility of selfassessment of dysphoric mania in the French national EPIMAN study. Journal of Affective Disorders, 67, 97-103. 
Henry, C., Lacoste, J., Bellivier, F., Verdoux, H., Bourgeois, M. L., \& Leboyer, M. (1999). Temperament in bipolar illness: impact on prognosis. Journal of Affective Disorders, 56, 103-108.

Henry, C., Sorbara, F., Lacoste, J., Gindre, C., \& Leboyer, M. (2001). Antidepressant-induced mania in bipolar patients: Identification of risk factors. The Journal of Clinical Psychiatry, 62, 249-255.

Homberg, J. R. \& Lesch, K. P. (2011). Looking on the bright side of serotonin transporter gene variation. Biol Psychiatry, 69, 513-9.

Judd, L. L. \& Akiskal, H. S. (2000). Delineating the longitudinal structure of depressive illness: beyond clinical subtypes and duration thresholds. Pharmacopsychiatry, 33, 3-7.

Kang, J. I., Namkoong, K. \& Kim, S. J. (2008). The association of 5-HTTLPR and DRD4 VNTR polymorphisms with affective temperamental traits in healthy volunteers. Journal of Affective Disorders, 109, 157-63.

Kapczinski, F., Dias, V. V., Kauer-Sant'anna, M., Brietzke, E., Vazquez, G. H., Vieta, E., \& Berk, M. (2009). The potential use of biomarkers as an adjunctive tool for staging bipolar disorder. Progress in Neuro-Psychopharmacology \& Biological Psychiatry, 33, 1366-1371.

Kapczinski, F., Vieta, E., Andreazza, A.C., Frey, B.N., Gomes, F.A., Traniontina, J., Kauer-Sant'anna, M., Grassi-Oliveira, R., Post, R.M. 2008. Allostatic load in bipolar disorder: Implications for pathophysiology and treatment. Neuroscience \& Biobehavioral Reviews, 32, 675-692.

Karg, K., Burmeister, M., Shedden, K., \& Sen, S. (2011). The Serotonin Transporter Promoter Variant (5-HTTLPR), Stress, and Depression Metaanalysis Revisited Evidence of Genetic Moderation. Archives of General Psychiatry, 68, 444-454.

Kawamura, Y., Liu, X. X., Akiyama, T., Shimada, T., Otowa, T., Sakai, Y., ... Akiskal, H. S. (2010). The association between oxy tocin receptor gene (OXTR) polymorphisms and affective temperaments, as measured by TEMPS-A. Journal of Affective Disorders, 127, 31-37.

Kelsoe, J. R. (2003). Arguments for the genetic basis of the bipolar spectrum. Journal of Affective Disorders, 73, 183-197. 
Kesebir, S., Vahip, S., Akdeniz, F., \& Yuncu, Z. (2005a). The relationship of affective temperament and clinical features in bipolar disorder. Türk Psikiyatri Dergisi, 16, 164-169.

Kesebir, S., Vahip, S., Akdeniz, F., Yuncu, Z., Alkan, M., \& Akiskal, H. (2005b). Affective temperaments as measured by TEMPS-A in patients with bipolar I disorder and their first-degree relatives: a controlled study. Journal of Affective Disorders, 85, 127-133.

Kochman, F. J., Hantouche, E. G., Ferrari, P., Lancrenon, S., Bayart, D., \& Akiskal, H. S. (2005). Cyclothyrnic temperament as a prospective predictor of bipolarity and suicidality in children and adolescents with major depressive disorder. Journal of Affective Disorders, 85, 181-189.

Kraepelin, E. (1921). Manic-Depressive Illness and Paranoia. Edinburgh: Livingstone.

Kuehner, C. (2003). Gender differences in unipolar depression: an update of epidemiological findings and possible explanations. Acta Psychiatrica Scandinavica, 108, 163-74.

Landaas, E. T., Johansson, S., Halmoy, A., Oedegaard, K. J., Fasmer, O. B., \& Haavik, J. (2011). No association between the serotonin transporter gene polymorphism 5-HTTLPR and cyclothymic temperament as measured by TEMPS-A. Journal of Affective Disorders, 129, 308-312.

Lazary, J., Lazary, A., Gonda, X., Benko, A., Molnar, E., Hunyady, L., ... Bagdy, G. (2009). Promoter Variants of the Cannabinoid Receptor 1 Gene (CNR1) in Interaction With 5-HTTLPR Affect the Anxious Phenotype. American Journal of Medical Genetics Part B, 150B, 1118-1127.

Levinson, D. F. (2006). The genetics of depression: A review. Biological psychiatry, 60, 84-92.

Lewinsohn, P. M., Klein, D. N., Durbin, E. C., Seeley, J. R., \& Rohde, P. (2003). Family study of subthreshold depressive symptoms: risk factor for MDD? Journal of Affective Disorders, 77, 149-157.

Lohoff, F. W. (2010). Overview of the genetics of major depressive disorder. Current Psychiatry Reports, 12, 539-46. 
Matsumoto, S., Akiyama, T., Tsuda, H., Miyake, Y., Kawamura, Y., Noda, T., ... Akiskal, H. S. (2005). Reliability and validity of TEMPS-A in a Japanese nonclinical population: application to unipolar and bipolar depressives. Journal of Affective Disorders, 85, 85-92.

Mazzarini, L., Pacchiarotti, I., Colom, F., Sani, G., Kotzalidis, G.D., Rosa, A.R., ... Vieta, E. (2009). Predominant polarity and temperament in bipolar and unipolar affective disorders. Journal of Affective Disorders, 119, 28-33.

Mechri, A., La Kerkeni, N., Touati, I., Bacha, M., \& Gassab, L. (2011). Association between cyclothymic temperament and clinical predictors of bipolarity in recurrent depressive patients. Journal of Affective Disorders, 132, 285-288.

Mendlowicz, M. V., Jean-Louis, G., Kelsoe, J. R., \& Akiskal, H. S. (2005). A comparison of recovered bipolar patients, healthy relatives of bipolar probands, and normal controls using the short TEMPS-A. Journal of Affective Disorders, 85, 147-151.

Neves-Pereira, M., Mundo, E., Muglia, P., King, N., Macciardi, F., \& Kennedy, J. L. (2002). The brain-derived neurotrophic factor gene confers susceptibility to bipolar disorder: evidence from a family-based association study. The American Journal of Human Genetics, 71, 651-5.

Oedegaard, K. J., Syrstad, V. E. G., Morken, G., Akiskal, H. S., \& Fasmer, O. B. (2009). A study of age at onset and affective temperaments in a Norwegian sample of patients with mood disorders. Journal of Affective Disorders, 118, 229-233.

Perugi, G., Toni, C., Maremmani, I., Tusini, G., Ramacciotti, S., Madia, A., ... Akiskal, H. S. (2012). The influence of affective temperaments and psychopathological traits on the definition of bipolar disorder subtypes: A study on Bipolar I Italian National sample. Journal of Affective Disorders, 136, E41-E49.

Perugi, G., Toni, C., Travierso, M. C., \& Akiskal, H. S. (2003). The role of cyclothymia in atypical depression: toward a data-based reconceptualization of the borderline-bipolar II connection. Journal of Affective Disorders, 73, $87-98$.

Rihmer, Z. (1980). Season of birth and season of hospital admission in bipolar depressed female patients. Psychiatry Research, 3, 247-51. 
Rihmer, Z., Erdos, P., Ormos, M., Fountoulakis, K.N., Vazquez, G., Pompili, M., $\&$ Gonda, X. (2011). Association between affective temperaments and season of birth in a general student population. Journal of Affective Disorders, 132, 64-70.

Rottig, D., Rottig, S., Brieger, P., \& Marneros, A. (2007). Temperament and personality in bipolar I patients with and without mixed episodes. Journal of Affective Disorders, 104, 97-102.

Sen, S., Burmeister, M., \& Ghosh, D. (2004). Meta-analysis of the association between a serotonin transporter promoter polymorphism (5-HTTLPR) and anxiety-related personality traits. American Journal of Medical Genetics Part $B, 127 \mathrm{~B}, 85-89$.

Serafini, G., Pompili, M., Innamorati, M., Fusar-Poli, P., Akiskal, H. S., Rihmer, Z., ... Tatarelli, R. (2011). Affective temperamental profiles are associated with white matter hyperintensity and suicidal risk in patients with mood disorders. Journal of Affective Disorders, 129, 47-55.

Sklar, P., Gabriel, S. B., Mcinnis, M. G., Bennett, P., Lim, Y.M., Tsan, G., ... Lander, E. S. (2002). Family-based association study of 76 candidate genes in bipolar disorder: BDNF is a potential risk locus. Brain-derived neutrophic factor. Molecular Psychiatry, 7, 579-93.

Sole, B., Bonnin, C. M., Torrent, C., Martinez-Aran, A., Popovic, D., TabaresSeisdedos, R., \& Vieta, E. (2012). Neurocognitive Impairment Across the Bipolar Spectrum. CNS Neurosc Therap, 18, 194-200.

Somers, J. M., Goldner, E. M., Waraich, P., \& Hsu, L. (2006). Prevalence and incidence studies of anxiety disorders: a systematic review of the literature. Canadian Journal of Psychiatry, 51, 100-13.

Thompson, J. M., Gallagher, P., Hughes, J. H., Watson, S., Gray, J. M., Ferrier, I. N., \& Young, A. H. (2005). Neurocognitive impairment in euthymic patients with bipolar affective disorder. The British Journal of Psychiatry, 186, 32-40.

Tondo, L., Baldessarini, R. J., Vazquez, G., Lepri, B., Visioli, C. (2013). Clinical responses to antidepressants among 1036 acutely depressed patients with bipolar or unipolar major affective disorders. Acta Psychiatrica Scandinavica, 127, 355-364. 
Tsutsumi, T., Terao, T., Hatanaka, K., Goto, S., Hoaki, N., \& Wang, Y. M. (2011). Association between affective temperaments and brain-derived neurotrophic factor, Glycogen synthase kinase 3 beta and Wnt signaling pathway gene polymorphisms in healthy subjects. Journal of Affective Disorders, 131, 353-357.

Vazquez, G. H. \& Gonda, X. (2013). Affective Temperaments and Mood Disorders: A Review of Current Knowledge. Current Psychiatry Reviews, 9, 21-32.

Vazquez, G. H., Kahn, C., Schiavo, C. E., Goldchluk, A., Herbst, L., Piccione, M., ... Akiskal, H. S. (2008). Bipolar disorders and affective temperaments: A national family study testing the "endophenotype" and "subaffective" theses using the TEMPS-A Buenos Aires. Journal of Affective Disorders, 108, 25-32.

Vazquez, G. H., Tondo, L., Mazzarini, L., \& Gonda, X. (2012). Affective temperaments in general population: A review and combined analysis from national studies. $J$ Affect Disord, 139, 18-22.

Zandi, P. P., Belmonte, P. L., Willour, V. L., Goes, F. S., Badner, J. A., Simpson, S. G., ... Potash, J. B. (2008). Association study of Wnt signaling pathway genes in bipolar disorder. Archives of General Psychiatry, 65, 785-93.

Zhang, K. R., Yang, C. X., Xu, Y., Sun, N., Yang, H., Liu, J. L., ... Shen, Y. (2010). Genetic association of the interaction between the BDNF and GSK3B genes and major depressive disorder in a Chinese population. Journal of Neural Transmission, 117, 393-401. 
